to enhance their skills in minimally invasive thoracic surgery by spending a one- or two-day period at clinical sites. Deadline: February 15, 2016

Graham Surgical Investigator Program: The Graham Surgical Investigator Program supports innovative clinical or translational research for young Cardiothoracic Surgeons including but not limited to topics related to outcomes research, as well as robotically assisted surgery, minimally invasive surgery, or other applications of new and innovative technologies in cardiothoracic surgery. Deadline: February 15, 2016

\section{Congratulations to our 2015 Awardees}

Evarts A. Graham Traveling Fellowship

Dr Konrad Hoetzenecker of the University of Vienna was selected as the 2016-2017 AATS Graham Traveling Fellow. Dr Hoetzenecker's Fellowship year will begin at the 2016 AATS Annual Meeting and will take place at Toronto General Hospital in Toronto, Ontario, Canada under the primary sponsorship of Dr Thomas K. Waddell.

\section{Third Robert E. Gross Research Scholarship}

Dr Matthew D. Taylor was selected by the AATS as the Third Robert E. Gross Research Scholarship.

Dr Taylor's two-year research scholarship at Penn State Milton S. Hershey Medical Center will begin in July 2016.

Advanced Valve Disease Educational FellowshipSponsored by Medtronic

Govind Chetty, MD-University Hospital of Wales, United Kingdom

Andrea Colli, MD_University of Padua, Italy

Evaldas Girdauskas, MD-Central Hospital Bad Berka, Germany

Francisco Guzmán, MD—Hospital Español De Mendoza, Argentina

Paradorn Jetwanna, MD—Suratthani Hospital, Thailand
Vasily Kaleda, MD—Kuban State Medical University, Russia

2015 Fellows for Advanced Minimally Invasive Thoracic Surgery-Sponsored by Ethicon

Ki Wan Kim, MD—NorthShore University Health System, Evanston, IL

John F. Lazar, MD-Pinnacle Health Cardiovascular Institute, Harrisburg, PA

Gholam R. Mohammadzadeh, MD—Los Robles Hospital, Thousand Oaks, CA

James L. Cox Fellowship in Atrial Fibrillation Surgery-Sponsored by AtriCure

Safak Alpat, MD-Hacettepe University School of Medicine, Department of Cardiovascular Surgery, Turkey

Chadrick Cross, MD-Advocate Christ Medical Center, US

Atsushi Hiromoto, MD-M.M. Amosov National Institute of Cardiovascular Surgery, Japan

Dong Seop Jeong, MD—Samsung Medical Center, Republic of Korea

Paradorn Jetwanna, MD — Suratthani Hospital, Thailand Justin Reeves, MD-University of Colorado School of Medicine, Anschutz Medical Campus

Eske Sindby, MD — Aalborg University Hospital, Denmark Zhiwei Xu, MD_-Department of Cardiothoracic Surgery, Xinhua Hospital, Shanghai Jiao Tong

AAATS Graham Foundation Academic Excellence Award

Dr Calogera Pisano

Best Work in Progress Presentation on Innovation and Scientific Research

29th EACTS Annual Meeting-Amsterdam, The Netherlands

Dr Lieven Depypere

Best Scientific Contribution on Esophageal Disease 23rd European Conference on General Thoracic Surgery—Lisbon, Portugal

\section{The Western Thoracic Surgical Association}

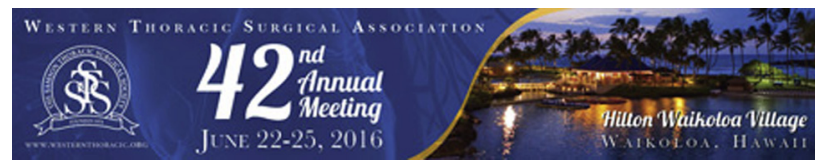

\section{NEW: WTSA Traveling Fellowship for Residents, Trainees, and Practicing Surgeons}

The goal of this new WTSA Traveling Fellowship is to promote interaction and learning between residents/trainees/ practicing surgeons and WTSA members. The traveling fellow will visit a University-affiliated or academic practice of his/her choosing, within the boundaries of the WTSA, for a period of one to two weeks, under the sponsorship of a Western member at the hosting institution. The traveling fellow does not need to be a WTSA member; the award is open to any resident/trainee/practicing surgeon. Reimbursement of up to $\$ 5,000$ will be provided to the traveling fellow to defray reasonable costs for travel, lodging, and meals.

To be eligible for consideration, the following materials should be submitted to the Association Office via the online application at www.westernthoracic.org no later than December 15, 2015: 